\title{
EVALUATION OF GENE XPERT MTB/RIF ASSAY FOR THE DETECTION OF Mycobacterium tuberculosis IN SPUTUM OF PATIENTS SUSPECTED OF PULMONARY TUBERCULOSIS VISITING NATIONAL TUBERCULOSIS CENTRE, THIMI, BHAKTAPUR, NEPAL
}

\author{
Thapa $A^{1}$, Gurung $P^{1}$, Ghimire $\mathbf{G R}^{2}$ \\ ${ }^{1}$ Department of Microbiology, St. Xavier College, Maitighar, Kathmandu, Nepal \\ ${ }^{2}$ National Tuberculosis Centre, Thimi, Bhaktapur, Nepal
}

\begin{abstract}
Introduction: Tuberculosis (TB) is one of the most deadly and common major infectious diseases in developing countries. Rapid and accurate diagnosis of tuberculosis is indispensable to adequately manage the disease and control its transmission. The objective of this study was to evaluate Gene Xpert MTB/RIF Assay for detection of $M$. tuberculosis in sputum of patients suspected of pulmonary tuberculosis and its comparison with traditional conventional methods.

Methodology: A total of 138 patients sputum samples were collected and processed. Gene Xpert MTB/ RIF Assay, culture method and smear microscopy were performed under standard guideline inside biosafety cabinet class II. Data were reported, structured and analyzed using SPSS version 16.00. Study was carried out from June to November 2014.

Results: Assay detected M. tuberculosis in $37(26.81 \%)$ samples out of total 138 . Of these 37,10 and 3 were resistance and indeterminate to rifampicin respectively. Culture, Ziehl-Neelsen staining and Auramine staining were positive in $43(31.16 \%), 18(13.04 \%)$ and 24 (17.39\%) samples respectively. Sensitivity, specificity, Positive predictive value and Negative predictive value of Assay were $76.74 \%$, $95.79 \%, 89.19 \%$ and $90.09 \%$ respectively with reference to gold standard culture method.

Conclusions: Assay was found rapid in direct detection of Mycobacterium tuberculosis in sputum sample and was also found more sensitive than both Ziehl-Neelsen staining and Auramine staining and especially showed good promise in diagnosis of smear negative specimens.
\end{abstract}

Key words: Gene Xpert MTB/RIF Assay, M. tuberculosis, Pulmonary Tuberculosis

\section{INTRODUCTION}

HIV Tuberculosis (TB) is one of the most deadly and common major infectious diseases in developing and industrialized countries. ${ }^{1}$ Tuberculosis in human is most commonly caused by Mycobacterium tuberculosis complex (MTBC), which includes $M$. tuberculosis, $M$. bovis, $M$. bovis $B C G$ and $M$. africanum and among them $M$. tuberculosis is predominant. ${ }^{2}$ In 2013, an estimated

\section{Correspondence:}

Mr. Ashok Thapa

Department of Microbiology, St. Xavier College,

Maitighar, Kathmandu, Nepal

E-mail: asok_67@yahoo.com
9.0 million people developed TB and 1.5 million died from the disease. ${ }^{1}$ In Nepal, tuberculosis (TB) is a major public health problem. About 45 percent of the total population is infected with TB, of which 60 percent are adult. Every year, 45,000 people develop active TB, of whom 20,580 have infectious pulmonary disease. ${ }^{3}$ Rapid and accurate diagnosis of tuberculosis (TB) is indispensable to adequately manage the disease and control its transmission. Acid-fast bacilli (AFB) smear microscopy sensitivity is low, varying between 22 and $80 \%$. And culture takes several weeks to provide microbiological confirmation. Nucleic acid amplification techniques can be used for detection of $M$. tuberculosis results in accurate diagnosis of tuberculosis but requires laborious processing time and dedicated bio-safety conditions. ${ }^{4}$ 
Tuberculosis spread has been increasing day by day in low income country like Nepal. This is because of delay in diagnosis which has thwarted the efficient management of the disease control. Rapid diagnostic procedure being simple to operate, cost effective, less bio-hazardous to perform within limited space and with good sensitivity along with specificity is most wanted in a country like Nepal in order to tackle the rapturous distribution of pulmonary tuberculosis. With such problems in consideration and to evolve the diagnostic pattern in new level with the use of rapid technology that has been accredited by WHO recently, this present study has endeavored to evaluate the Gene Xpert MTB/RIF Assay, an automated polymerase chain reaction (PCR) test with culture, Ziehl-Neelsen staining and Auramine staining, especially between Gene Xpert MTB/RIF Assay and Culture followed by different biochemical tests for the identification of M. tuberculosis. Gene Xpert MTB/ RIF assay detects the presence of MTBC DNA and its susceptibility to rifampin in a single reaction. Mono-resistance to rifampicin is rare; however, $90 \%$ of rifampicin resistant isolates also exhibit resistance to isoniazid. Therefore, the detection of rifampicin resistance may serve as a surrogate marker for MDR M. tuberculosis. The assay is based on a heminested real-time PCR (RT-PCR) that targets the $r p o B$ gene hot spot region. Any deviation from the wild type sequence resulting in a delay in the appearance of the signal exceeding a predetermined $C T$ value, between the earliest and latest cycle threshold $(C T)$ values is reported as RIF resistant. The test is carried out within $2 \mathrm{~h}$ in a disposable cartridge. The only manual step is the mixing of a bactericidal buffer with the sample prior to addition to the cartridge. This pre-amplification step reduces the viability of MTBC organisms, making the assay suitable for use near patients in settings with limited bio-containment facilities. ${ }^{5}$

This study has significant importance in rapid diagnosis of tuberculosis of patients suspected of pulmonary tuberculosis. Additional to diagnosis, this study has importance in direct detection of rifampicin resistance which therefore can provide the basis for prompt treatment of drug resistance tuberculosis. And this study can be valuable in improvising the tuberculosis diagnostic field for the betterment of minimizing the insidious distribution of pulmonary tuberculosis from infected person to healthy individual. Present study with scrupulous details and comprehensive understanding about rapid and effective diagnosis of pulmonary tuberculosis may evolve insight on use of Gene Xpert MTB/RIF Assay throughout the country in achieving the target of treating all the infected patients of tuberculosis and therefore might helps in curbing rapturous distribution of tuberculosis.

\section{METHODOLOGY}

\section{Study design, site and setting}

The study was a hospital based cross-sectional study carried out in National Tuberculosis Centre, Thimi, Bhaktapur, Nepal. Astructured questionnaire was prepared and interview of patients were taken with their informed consent. Data were collected based around patient's personal description and tuberculosis background.

\section{Study population and time period}

In this study, patient those who were suspected of pulmonary tuberculosis, willing to participate and responding to study designed format questionnaire were considered as study population. And the study period was carried out from June to November in 2014.

\section{Inclusion/ Exclusion criteria}

Patients clinically suspected of pulmonary tuberculosis were involved in this study. And patients recently undergoing anti-tuberculosis treatment, blood stained sputum, sputum with food particles, with saliva in greater amount, leaking, dried or if not fresh collection and patients suspected of extra-pulmonary tuberculosis were excluded from this study.

\section{Sample size}

One thirty eight patients were involved in this study, which was determined by sample size calculation using Fischer's formula outlined as $n=\left[Z^{2} p q\right] / d^{2}$.

\section{Sample collection}

Patient morning sputum sample of about $5 \mathrm{ml}$ was collected in a clean, wide neck, screw capped and disposable plastic (50 ml Tarson falcon) tube. Samples collected were evaluated directly with naked eyes through transparent tube and selected sample tubes were labeled with patient name and lab number serially and processing of sample was carried out in a bio-safety cabinet II. 


\section{Gene Xpert MTB/RIF Assay}

$1 \mathrm{ml}$ sputum sample in falcon tube was mixed with $2 \mathrm{ml}$ sample reagents and vortexed until clear solution was made and left for 15 minutes. And $2 \mathrm{ml}$ mixture was transferred into the Xpert MTB/RIF cartridge using sterile dropper. The Xpert MTB/RIF cartridge includes an internal control for sample processing (DNA extraction and for PCR presence inhibitors), afterwards the inoculated cartridge was placed into the Gene Xpert instrument. Results were available in less than 2 hours and interpreted by the Gene Xpert System automatically. For all samples, Assay was carried out only once with meticulous attention.

\section{Smear microscopy and Culture}

Sputum sample were processed using standard petroff's method. Freshly prepared $\mathrm{NaOH}$ solution was added to the specimen at equal volume, mixed using vortex, and left for 15 minutes for digestion at room temperature. A double amount of sterile phosphate buffer was then added to the mixture and centrifuged for 20 minutes at $300 \times \mathrm{g}$. The supernatant was removed and the sediment was dissolved in few $\mathrm{ml}$ of sterile phosphate. And the solution was used for smear microscopy and culture. Smears were prepared, fixed, and Z-N and Auramine staining were performed and observed under standard guidelines. In culture, LowensteinJensen medium was used for inoculation and inoculated LJ media were incubated at $37^{\circ} \mathrm{C}$ for 8 weeks and examined weekly. Positive cultures of Mycobacterium isolates were compared with control H37Rv M. tuberculosis and 1-2 weeks fresh colonies on LJ media were used for biochemical tests (viz. Niacin and Catalase tests). Biochemical tests were performed under standard guideline protocol of WHO 2013. And for each sample, replicates were also performed on juxtaposition wise. All the diagnostic tests were performed inside bio-safety cabinet class II.

\section{Ethical consideration}

All the suspected pulmonary tuberculosis patients involved in this study were enrolled with their informed consent by counseling them and making them understood the information about the study regarding the confidentiality and implication of the result.

\section{Data analysis}

The data were collected, structured and analysis was done using SPSS version 16.0 System. Statistical analysis (i.e. Chi-Square) was employed on determining the association of different variables involved in the study in distribution of pulmonary tuberculosis at $5 \%$ level of significance.

\section{RESULT}

Out of 138 samples, 37 (26.81\%) and 40 (28.98\%) were confirmed positive to $M$. tuberculosis in sputum samples using test methods, viz. Gene Xpert MTB/ RIF Assay and Culture followed by biochemical tests respectively. And among 26 smears positive, $21(80.76 \%)$ and $23(88.46 \%)$ were confirmed as M. tuberculosis detected by Assay and culture respectively. Culture was positive on $43(31.16 \%)$ out of 138 samples. Of these 43 culture positive samples, $33(76.74 \%)$ were found positive by Gene Xpert MTB/RIF Assay. Z-N staining was positive on $18(13.04 \%)$ out of 138 samples. Assay was found positive in all Z-N smear positive specimens except on 2 i.e. 16 (88.89\%). Auramine staining was positive in $24(17.39 \%)$ out of 138 samples. And of 24 auramine smear positive specimens, assay was found positive on $20(83.33 \%)$, whereas $4(16.67 \%)$ were negative.

On age wise distribution, 18 (35.29\%) out of 51 being highest and 3 out of $27(11.11 \%)$ being lowest number of patients in age group 16-30 and 31-45 were diagnosed positive to PTB respectively. On gender wise distribution $10(25 \%)$ female patient and $27(27.55 \%)$ male patients were diagnosed with pulmonary tuberculosis (PTB). Statistically, there was no significant association in both age wise and gender wise distribution with pattern of pulmonary tuberculosis. On smoking, alcohol consumption and on history of TB wise distribution of pulmonary tuberculosis, $23(35.39 \%)$ out of 65 smokers, $20(40 \%)$ out of 50 who drink alcohol and $15(46.87 \%)$ out of 32 patients with history of TB were diagnosed with PTB respectively. And statistically there was significant association of all variables in distribution with pattern of PTB. Sensitivity, Specificity, Positive predictive value and Negative predictive value of Gene Xpert MTB/ RIF Assay with reference to culture in the diagnosis of PTB was $76.74 \%, 95.79 \%, 89.19 \%$ and $90.09 \%$ respectively. 


\begin{tabular}{|c|c|c|c|c|c|}
\hline \multirow{3}{*}{$\begin{array}{l}\text { Smear microscopy } \\
\text { result }\end{array}$} & \multicolumn{5}{|c|}{ Gene Xpert MTB/RIF Assay and Culture result } \\
\hline & \multirow{2}{*}{\multicolumn{2}{|c|}{ Gene Xpert MTB/RIF Assay Result }} & \multicolumn{2}{|c|}{ Positive culture for MTB detection } & \multirow{2}{*}{$\begin{array}{l}\text { No. of Negative } \\
\text { culture or culture } \\
\text { contaminated }\end{array}$} \\
\hline & & & $\begin{array}{c}\text { Niacin test } \\
\text { Positive }\end{array}$ & $\begin{array}{l}\text { Catalase test } \\
\text { positive }\end{array}$ & \\
\hline \multirow{3}{*}{$\begin{array}{l}\text { Smear positive } \\
\text { specimens (26) }\end{array}$} & M. tuberculosis detected & $21(80 \%)$ & $23(88.46 \%)$ & 0 & 0 \\
\hline & M. tuberculosis not detected & 5 & 0 & 0 & 0 \\
\hline & Not interpretable & 0 & 0 & 0 & 3 \\
\hline \multirow{3}{*}{$\begin{array}{l}\text { Smear negative } \\
\text { specimens (112) }\end{array}$} & M. tuberculosis detected & $16(14.28 \%)$ & $17(15.19 \%)$ & 0 & 0 \\
\hline & M. tuberculosis not detected & 96 & 0 & 3 & 0 \\
\hline & Not interpretable & 0 & 0 & 0 & 92 \\
\hline
\end{tabular}

\begin{tabular}{|c|c|c|c|c|c|}
\hline S. No. & & & Total count & Positive (\%) & $p$-value* \\
\hline \multirow[t]{2}{*}{1} & \multirow[t]{2}{*}{ Smoking } & Yes & 65 & $23(35.39 \%)$ & \multirow[t]{2}{*}{$p<0.05$} \\
\hline & & No & 73 & 14 (19.17\%) & \\
\hline \multirow[t]{2}{*}{2} & \multirow[t]{2}{*}{ Alcohol consumption } & Yes & 50 & $20(40 \%)$ & \multirow[t]{2}{*}{$\mathrm{P}<0.05$} \\
\hline & & No & 88 & $17(19.32 \%)$ & \\
\hline \multirow[t]{2}{*}{3} & \multirow[t]{2}{*}{ History of TB } & Yes & 32 & $15(46.87 \%)$ & \multirow[t]{2}{*}{$P<0.05$} \\
\hline & & No & 106 & $22(20.75 \%)$ & \\
\hline
\end{tabular}

*at $5 \%$ level of significance

Table 3. Sensitivity, specificity, positive predictive value and negative predictive value of Gene Xpert MTB/RIF Assay in reference to gold standard culture method

\begin{tabular}{|l|c|c|c|c|}
\hline \multirow{2}{*}{ Diagnostic method } & \multicolumn{4}{|c|}{ Gold standard Culture method } \\
\cline { 2 - 5 } & $\begin{array}{l}\text { Sensitivity } \\
\text { (\%) }\end{array}$ & Specificity (\%) & Positive Predictive value (\%) & Negative Predictive value (\%) \\
\hline Gene Xpert MTB/RIF Assay & $76.74 \%$ & $95.79 \%$ & $89.19 \%$ & $90.09 \%$ \\
\hline Z-N Acid Fast Staining & $39.53 \%$ & $98.94 \%$ & $94.44 \%$ & $78.33 \%$ \\
\hline Auramine Staining & $48.84 \%$ & $96.84 \%$ & $87.5 \%$ & $80.70 \%$ \\
\hline
\end{tabular}

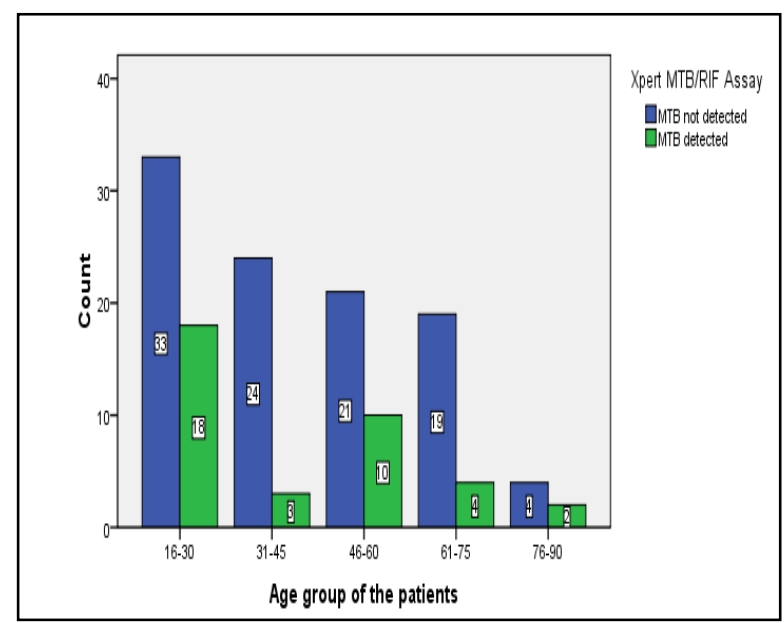

Figure 1. Age wise distribution of pulmonary tuberculosis according to Gene Xpert MTB/RIF Assay

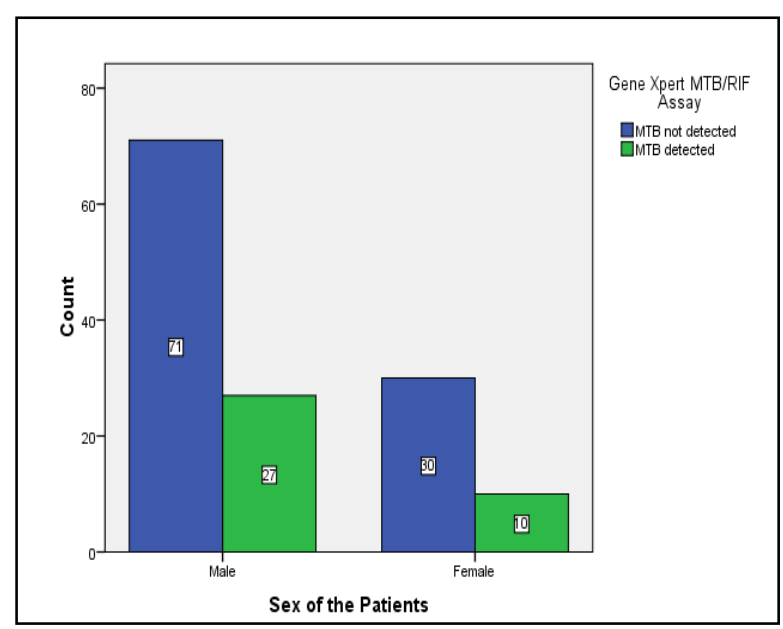

Figure 2. Gender wise distribution of pulmonary tuberculosis according to Gene Xpert MTB/RIF Assay 


\section{DISCUSSION}

Tuberculosis (TB) has troubled humankind throughout history. Tuberculosis (TB) is an ancient disease that has affected mankind for more than 4,000 years. It is a chronic disease caused by the bacillus $M$. tuberculosis and spreads from person to person through air. ${ }^{6}$ In 2013, 6.1 million TB cases were reported by WHO. Of these, 5.7 million were newly diagnosed. ${ }^{1}$ Tuberculosis is the most widespread infectious disease in Nepal and poses a serious threat to the health and development of the country. ${ }^{3}$ Distribution of tuberculosis is still going on despite DOTS implementation in most parts of the country. This is all because of delay in diagnosis which leads to delay in treatment, as well as inadequate presence of rapid, accurate technique in tuberculosis diagnosis which has also favored the transmission of the disease. And in-order to tackle such problem, present study has evaluated the Gene Xpert MTB/RIF Assay's efficacy in the diagnosis of pulmonary tuberculosis, in which assay was successful in directly detecting M. tuberculosis as well as rifampicin susceptibility pattern simultaneously.

This hospital based cross-sectional study was performed, observed and analyzed by being within the scope and objective of the study. This study was successful in diagnosis of pulmonary tuberculosis using Gene Xpert MTB/RIF Assay and in the comparative study with traditional conventional methods such as commonly used smear microscopy (i.e. Ziehl Neelson and Auramine staining) and gold standard culture method. In this study, patients aged above 15 suspected of pulmonary tuberculosis were enrolled since there was difficult in extraction of enough sputum samples from the children and no extra-pulmonary samples were accommodated.

On examination of 138 patient's clinical sputum, assay was successful in identifying $M$. tuberculosis from $37(26.81 \%)$ sputum samples. And simultaneous rifampicin resistance was detected in $10(7.24 \%)$ M. tuberculosis while $3(2.17 \%)$ M. tuberculosis were rifampicin indeterminate. Assay showed that it was rapid in detection of $M$. tuberculosis directly from clinical sputum and in simultaneous detection of rifampicin resistance. And this finding was in agreement with other studies. ${ }^{7,8}$ In general regarding the assay, the basis for the direct detection of $M$. tuberculosis is that probes present within molecular beacon was successful in forming complementary bond with entire 81rpo gene of $M$. tuberculosis with a cycle threshold (CT) of $\leq 38$ cycles. Rifampicin resistance is particularly amenable to rapid molecular detection since $>95 \%$ of all rifampicin resistant strains contain mutations localized within the $81 \mathrm{bp}$ core region of the $M$. tuberculosis RNA polymerase $r p o B$ gene, which encodes the active site of the enzyme. Moreover, mutations that occur in this region are highly predictive of rifampicin resistance, whereas susceptible isolates almost always have the same wild-type nucleotide sequence. And the basis for rifampicin indeterminate is when the first probe $\mathrm{CT}$ is $>34.5$ and the last probe $\mathrm{CT}$ is $>38$ cycles. ${ }^{9}$ Assay and culture were almost positive to all smear positive specimens while they showed good promise in detection of $M$. tuberculosis in smear negative specimens as well. This finding was supported by other studies. ${ }^{10,2}$ And the result was evident because Assay and culture can detect bacilli as few as 131 and from $10-100$ cells $/ \mathrm{ml}$ of sputum respectively whereas smear microscopy is positive if only the bacilli number is at-least 10,000 cells $/ \mathrm{ml}$ of sputum. Regarding assay negativity in smear positive specimens, because Assay is specific to detect only MTB whereas both staining techniques used in this study, can detect both MTB and Non-tuberculosis mycobacteria in smear specimens. And regarding the assay inability to detect $M$. tuberculosis in sputum specimen which was positive in culture assisted by biochemical test seems to be contrary however this anomaly might have taken place since the analytical limit of detection of the Gene Xpert MTB/RIF assay is reported to be $131 \mathrm{cfu} / \mathrm{ml}$ of specimen, based on spiked sputum studies. Culture of concentrated specimens can detect very low concentrations of organisms as low as $10-100 \mathrm{cfu} / \mathrm{ml}$. When testing at the lower limits of any assay, variability is to be expected due to factors such as sampling. ${ }^{12}$ And other reason for such contradiction between culture positivity and assay negativity in same specimens occurred because only two available biochemical tests (viz. Niacin and $68^{\circ} \mathrm{C}$ heat stable catalase test) were used in the present study for identification without any further molecular characterization of $M$. tuberculosis.

On age wise distribution of pulmonary tuberculosis, age group 16-30 was found highest in PTB 
suspects of all age group which was in accordance with previous studies. ${ }^{6,13}$ Since this age group people are highly active, their chance of exposure is also high which support evidence of acquiring disease. On gender wise distribution, $10(25 \%)$ female patients and $27(27.55 \%)$ male patients were diagnosed with pulmonary tuberculosis (PTB). This result actually reflects the fact that males are more exposed to the outer environment than females, and there can be higher possibility that male might comes in contact with TB suspected or infected patient directly or indirectly which can lead to transmission of the disease. This result is in corresponds with other studies. ${ }^{13-15}$ However, present study showed that there was no significant association of both age and gender wise distribution with pattern of pulmonary tuberculosis. On smoking-wise distribution, smokers were found more susceptible to pulmonary tuberculosis than non-smokers which was in accordance with other studies. ${ }^{16-18}$ Smokers are more susceptible to tuberculosis because in cigarette there are more than 1000 chemicals which directly affect lungs affecting the normal functioning of immune cells that may favor the disease establishment in lungs. On alcohol consumption, those who drink alcohol frequently were found having pulmonary tuberculosis than who do not drink and it was in agreement with other studies. ${ }^{16,19}$ This may be due to both increased risk of infection related to specific social mixing patterns associated with alcohol use, as well as influence on the immune system of alcohol itself and of alcohol related conditions. And also on patients with history of TB, pulmonary tuberculosis was predominant than those who do not have. This might be due to poor treatment supervision, failure to follow-up smear microscopic observation and patient general conditions may lead to TB recurrence. This finding was in correspondence with previous studies. ${ }^{20,21}$

In present study, Assay showed much higher sensitivity than both Ziehl-Neelsen staining and Auramine staining which was in agreement with other study. ${ }^{22}$ But the specificity was lower than both staining technique. Positive predictive value of Assay was lower than Ziehl-Neelsen staining but was higher than Auramine staining. However Negative predictive value of assay was higher than both staining technique. Assay was found to be very sensitive than smear microscopy. Higher sensitivity of Assay compared to smear microscopy is universally evident since assay can detect as few as 131 bacilli per $\mathrm{ml}$ in sputum, whereas microscopy is able to detect bacilli if 10,000 cells per $\mathrm{ml}$ are present in sputum sample.

However in this study, few limitations were inevitable, because of the certain circumstances such as available HIV patients in the hospital were undergoing anti-retroviral therapy and TB treatment and thus were excluded from the study population. Because of limited time frame provided during the study period and incommodious lab space as well as unavailability of prerequisite factors for accommodating sample size, drug susceptibility test (DST) for both Rifampicin resistant and sensitive specimens were not carried out, which could have averred conformity to the present study. Despite all the reservation, this study was carried out at its best, remaining within the scope and objective of the study, maintaining and following WHO guidelines, ethics and moral values of the research. Moreover, from this study it is recommended that the further research needs to be done regarding the accurateness of Gene Xpert MTB/RIF Assay with reference to advanced molecular methods.

\section{CONCLUSION}

Present study has shown that assay can be potential alternative to smear microscopy especially in smear negative specimens despite the fact that assay is expensive than smear microscopy. However assay showed advantage over smear microscopy or even culture method, because of its rapidity, effectiveness and simultaneous detection of rifampicin resistance which leads to early treatment and thus provide aid in control of disease transmission. Gene Xpert MTB/RIF Assay has demonstrated a high capacity for detecting MTB and for predicting multidrug resistance in both smear positive and negative clinical sputum samples. Moreover, assay rapidity, simplicity, low laboriousness make the technique a good candidate for routine use in many clinical laboratories in our country to curb TB transmission given whenever the clinical criteria for its application are settled.

\section{Acknowledgements}

We are very grateful to NTC, Thimi, Bhaktapur and St. Xavier College, Maitighar, Kathmandu and the 
staffs of both college and hospital and as well as patients for their support and compliance during the study period.

\section{REFERENCES}

1. World Health Organization. Global Tuberculosis Report 2013. Geneva; WHO/HTM/TB/2013.11

2. Forbes BA, Sahm DF, Weissfeld AS. Mycobacteria. In Bailey and Scott's Diagnostic Microbiology. International Edition, (12 ${ }^{\text {th }}$ edn). Mosby Elsevier publisher, Philadelphia, PA, USA;2007.

3. National Tuberculosis Control Programme (NTP). Annual Report 2012/2013, Nepal, National Tuberculosis Programme, Thimi, Bhaktapur, Nepal.

4. Deggim V, Somoskovi A, Voit A, Bottger EC, Bloemberga GV. Integrating the Xpert MTB/ RIF Assay into a Diagnostic Workflow for Rapid Detection of Mycobacterium tuberculosis in a Low-Prevalence Area. J. Clin. Microbiol. 2013 Apr 24;51(7):2396-2399.

5. Ioannidis P, Papaventsis D, Karabela S. GeneXpert MTB/RIF Assay for M. tuberculosis Detection and Rifampin Resistance Identification in Patients with Substantial Clinical Indications of Tuberculosis and Smear-Negative Microscopy Results. J Clin Microbiol. 2011;49(8):3068-3070.

6. Chattu VK, Alzohairy M, Sahsah B, Barsamin F, Albelaihi M. Global health \& tuberculosis: A retrospective study. SAARC J. Tuberc. LUNG Dis. HIVIAIDS.2013;X(2).

7. Zeka AN, Tasbakan S, Cavusoglu C. Evaluation of the GeneXpert MTB/RIF Assay for Rapid Diagnosis of Tuberculosis and Detection of Rifampin Resistance in Pulmonary and Extrapulmonary Specimens. J Clin. Microbiol. 2011 Sept.28;49(28):4138-4141.

8. Hakeem A, Hussain MS, Sarwar MI. Gene Xpert MTB/RIF: A Novel Diagnostic Tool for Tuberculosis in Pulmonary Samples. J. Dent. and Med. Sci. 2013 Aug;8(2):01-03.

9. Lawn SD, Nicol MP. Xpert MTB/RIF assay: development, evaluation and implementation of a new rapid molecular diagnostic for tuberculosis and rifampicin resistance. Future Microbiol. 2011;6(9):1067-1082.

10. Al-Ateah SM, Al-Dowaidi MM, El-Khizzi NA. Evaluation of direct detection of Mycobacterium tuberculosis complex in respiratory and nonrespiratory clinical specimens using the Cepheid
Gene Xpert System. J. Saudi. Med. 2012 Mar;33(10):1100-1105.

11. Park KS, Kim JY, Lee JW, et al. Comparison of the Xpert MTB/RIF and Cobas TaqMan MTB Assays for Detection of Mycobacterium tuberculosis in Respiratory Specimens. J Clin Microbiol. 2013;51(10):3225-3227.

12. Marlowe EM, Novak-Weekley SM, Cumpio J, et al. Evaluation of Cepheid Xpert MTB/RIF Assay for the direct detection of Mycobacterium tuberculosis complex from respiratory specimens. J. Clin. Microbio. 2011 Apr;49(4):1621-1623.

13. Rao S. Tuberculosis and patient gender: An analysis and its implications in tuberculosis control. Lung India. 2009;26(2):46-47.

14. Marahatta SB, Kaewkungwal J, Ramasoota P, Singhasivanon P. Risk factors of Multidrug Resistant Tuberculosis in central Nepal: A pilot study. Kathmandu Univ. Med. J. 2010 Dec;8(32):392-397.

15. Kolappan C, Gopi PG, Subramani P, Narayanan R. Selected biological and behavioural risk factors associated with pulmonary tuberculosis. Int. J. Tuberc. Lung Dis. 2007 May 22;11(9):999-1003.

16. Narasimhan P, Wood J, Maclntyre CR, Mathai D. Risk Factors for Tuberculosis. Pulm. Med.2013;2013: 828939.

17. Alavi SM, Ershadian S. Association between cigratte smoking and pulmonary tuberculosis. Pak. J. Med. Sci. 2009;25(6):912-915.

18. Hassmiller KM. The association between smoking and tuberculosis. Salud Publica Mex. 2006; 48(1):S201-216.

19. Barclay L. Excessive Alcohol Intake May Increase Risk for Active Tuberculosis. BMC Public Health. 2009-2008;(8):289.

20. Chen W, Shu W, Wang M, et al. Pulmonary Tuberculosis Incidence and Risk Factors in Rural Areas of China: A Cohort Study. PLoS ONE. 2013;8(3): e58171.

21. Datiko DG, Lindtjorn B. Tuberculosis recurrence in smear-positive patients cured under DOTS in southern Ethiopia: Retrospective cohort study. BMC Public Health. 2009;9:348.

22. Dorman SE, Chihota VN, Lewis JJ, et al. Performance Characteristics of the Cepheid Xpert MTB/RIF Test in a Tuberculosis Prevalence Survey PLoS ONE. 2012;7(8):e43307. 